\title{
Enhancement of flow boiling heat transfer in microchannels by nano- and micro-surface treatments
}

\author{
Hai Trieu Phan ${ }^{1,2, a}$, Nadia Caney ${ }^{1}$, Philippe Marty ${ }^{1}$, Stéphane Colasson ${ }^{2}$ \\ AND JÉRÔME GAVILlET ${ }^{3}$ \\ 1 Université Joseph Fourier, LEGI, BP 53, 38041 Grenoble Cedex 9, France \\ 2 LITEN/LETH, CEA Grenoble, 17 rue des martyrs, 38054 Grenoble Cedex 9, France \\ 3 LITEN/LTS, CEA Grenoble, 17 rue des martyrs, 38054 Grenoble Cedex 9, France
}

Received 19 April 2011, Accepted 14 May 2011

\begin{abstract}
This paper investigates the flow boiling heat transfer in microchannels with the aim of developing compact cooling systems which can be adapted to miniaturized power components. Nano- and micro-surface treatments were used as innovative techniques to improve the heat transfer performance as well as to delay the intermittent dryout. It was observed that the micro-structured surfaces show significant enhancements (up to 85\%) in heat transfer compared to the smooth surfaces. Especially, using the highly-wetted structured surface, the intermittent dryout is improved.
\end{abstract}

Key words: Contact angle / convective boiling / microchannel / micro-patterning / nanocoating

Résumé - Amélioration du transfert thermique en ébullition convective dans les microcanaux par nano- et micro-structurations de surface. Cet article présente nos études sur le transfert thermique en ébullition convective dans les microcanaux dont l'objectif est de développer des systèmes de refroidissement compacts qui peuvent s'adapter aux composants de puissance miniaturisés. Les nano- et micro-structurations de surface ont été utilisées comme des techniques innovantes permettant d'améliorer la performance de transfert thermique et de retarder le phénomène d'assèchement intermittent. Il a été observé que les surfaces contenant des microstructures ont de meilleurs coefficients de transfert thermique par rapport aux surfaces lisses (jusqu'à $85 \%$ d'amélioration). En particulier, en rendant cette surface structurée plus mouillante, l'assèchement intermittent a significativement retardé.

Mots clés : Angle de contact / ébullition convective / microcanal / micro-stucturation / nano-structuration

\section{Introduction}

Power systems, such as electronic components or fuel cells, are dissipating more and more heat due to progressively increasing power densities associated with continuous advances in their miniaturization. In order to prevent damages to their components, this generated heat must be efficiently removed. Various cooling modes can be applied, such as air convection or liquid and boiling flows. Air convection is the most widely-used method because of its easy implementation. However, this mode exhibits a poor heat transfer performance and its operational limits have been already reached. As a consequence, cooling

\footnotetext{
a Corresponding author:

haitrieu.phan@laplace.univ-tlse.fr
}

\section{Nomenclature}

\begin{tabular}{|ll|}
\hline$C o$ & Confinement number \\
$D_{\mathrm{h}}$ & hydraulic diameter, $\mathrm{m}$ \\
$G$ & mass flux, kg.m ${ }^{-2} \cdot \mathrm{s}^{-1}$ \\
$h$ & heat transfer coefficient, $\mathrm{W} \cdot \mathrm{m}^{-2} \cdot \mathrm{K}^{-1}$ \\
$L_{\mathrm{c}}$ & capillary length, $\mathrm{m}$ \\
$P$ & pressure, Pa \\
$q$ & heat flux, W.m ${ }^{-2}$ \\
$T_{\mathrm{s}}$ & saturation temperature, $\mathrm{K}$ \\
$T_{\mathrm{w}}$ & wall temperature, $\mathrm{K}$ \\
$x$ & vapour quality \\
\hline
\end{tabular}

systems by liquid and boiling flows have been increasingly developed. Flow boiling is the most efficient mode as it 
provides better heat transfer efficiencies. Indeed, for this cooling mode, a part of heat is transferred into the latent heat during liquid-vapour phase change in addition to convective effects.

In the present study, flow boiling was generated inside the systems called mini- and microchannels, which are channels of small size with hydraulic diameters of less than $3 \mathrm{~mm}$. Over the last decade, mini- and microchannels have attracted the attention of researchers in the field of heat and mass transfer, because they enable the development of compact cooling systems which can be adapted to miniaturized power components. In order to distinguish between macro and microscale flow boiling, the threshold to confined bubble flow is one of the most widely used criterions. Following the classification by Kew and Cornwell [1], channels are classified as microchannels if $C o \geq 0.5$, where $C o$ is the confinement number defined as:

$$
C o=\frac{L_{\mathrm{c}}}{D_{\mathrm{h}}}
$$

wherein $L_{\mathrm{c}}$ is the capillary length and $D_{\mathrm{h}}$ is the hydrodynamic diameter. Kandlikar and Grande [2] suggested another classification based on the hydrodynamic diameter: conventional channels $\left(D_{\mathrm{h}}>3 \mathrm{~mm}\right)$, minichannels $\left(200 \mu \mathrm{m}<D_{\mathrm{h}}<3 \mathrm{~mm}\right)$ and micro-channels $\left(D_{\mathrm{h}}<\right.$ $200 \mu \mathrm{m})$.

For microscale flow boiling, the heat transfer coefficient can significantly decrease at low values of vapour quality due to intermittent dryout, which refers to an unstable breakdown of the liquid film in contact with the wall $[3-5]$. Intensification of the heat transfer coefficient and delay of the intermittent dryout are the main objectives of research in recent years [6]. On the microscale level, capillary effects become important and may play a significant role in the heat transfer mechanism. For instance, Phan et al. [7] showed that surface wettability affects the pool boiling heat transfer significantly. Modifying the surface wetting is thereby a reasonable solution to achieve the above objectives. Today, significant advances have been made in techniques of surface structuring at micro and nano scales, which enable significant modification of the surface wettability.

In the present study, experiments were performed to determine the effects of surface wettability on the flow boiling heat transfer. The test channel is rectangular with hydraulic diameter of $0.96 \mathrm{~mm}$ and length of $180 \mathrm{~mm}$. The confinement number is equal to 2.6 , and hence the test channel is considered as microchannel according to Kew and Cornwell theory [1], but as minichannel according to Kandlikar and Grande [2] classification. The local wall temperature and heat flux are directly measured. The channel geometry was precisely determined in order to reduce measurement uncertainties. The sample surfaces are produced by well-controlled processes by physical and chemical vapour depositions. For the first time, a complete set of experimental data is provided to explore the effects of micro-patterning and surface wettability on flow boiling heat transfer in a microchannel.

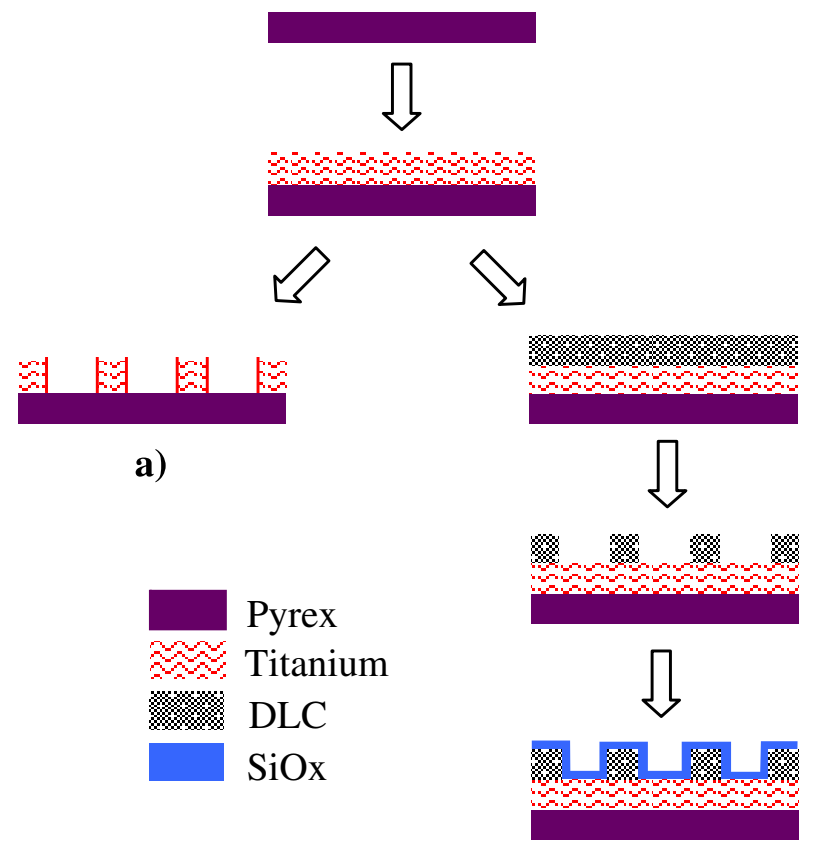

b)

Fig. 1. Side view of fabrication procedure of structured surfaces: (a) $\mu$-Ti surface and (b) $\mu$-SiOx surface.

\section{Experimental setup}

\subsection{Sample surfaces}

In order to determine the effects of micro-surface treatment, two sample surfaces were fabricated following the steps shown in Figure 1. The first sample is called " $\mu$ Ti". To produce this surface, a titanium layer was firstly deposited with a thickness of 3-4 $\mu \mathrm{m}$. Afterwards, microholes were made by laser etching through a patterning mask which contains holes with radius of $20 \mu \mathrm{m}$.

The second sample is called " $\mu$-SiO $x$ ", which is a structured surface of hydrophilic polydimethyl-siloxane $(\mathrm{SiO} x)$. At first, depositions of titanium (Ti, thickness of 3-4 $\mu \mathrm{m}$ ) and diamond-like carbon (DLC, thickness of $1 \mu \mathrm{m})$ were made. Then, the micro-holes were created by laser etching of the DLC layer through the same patterning mask used for the " $\mu$-Ti" surface. Finally, a deposition of $\mathrm{SiO} x$ layer is made on the surface of interest with a thickness of about $50 \mathrm{~nm}$.

The contact angles of water on the smooth and structured samples were measured using the sessile drop technique with KRÜSS EasyDrop systems in a cleanroom. Figure 2 illustrates images of water droplets on these surfaces. The obtained contact angles are $20^{\circ}$ and $65^{\circ}$ for the $\mu$-SiO $x$ surface and the $\mu$-Ti surface, respectively. Compared to the smooth samples, the $\mu$ - $\mathrm{SiO} x$ is more wetted and the $\mu$-Ti is less wetted.

\subsection{Experimental apparatus}

The channel is defined by putting a glass lid over the sample surface. This lid has a rectangular groove $5 \mathrm{~mm}$ 


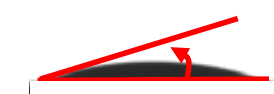

$20^{\circ}$ $\mu$-SiOx surface

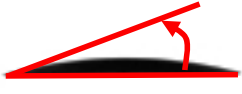

$26^{\circ}$ SiOx surface

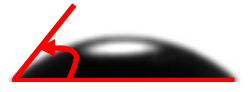

$49^{\circ}$ Ti surface

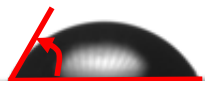

$65^{\circ}$ $\mu$-Ti surface

Fig. 2. Water droplets on the smooth and structured samples at the ambient temperature.

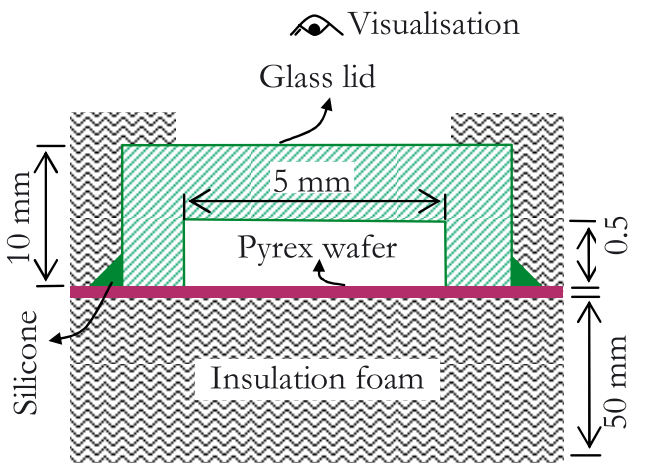

Fig. 3. Assembly of the test section.

wide, $0.5 \mathrm{~mm}$ deep and is bonded to the Pyrex wafer by vacuum aspiration as shown in Figure 3. To prevent fluid leakage, silicone compound is placed around the external contact between the glass cap and the Pyrex wafer. The sample surface is heated by Joule effects when a direct current crossing through the titanium layer. The test channel is thermally insulated with foam. Visualisation of the fluid flow can be made from the top of the glass lid. The experimental setup is shown in Figure 4. It consists of a test section, a condenser with a cooling bath, a liquid pump (ISMATEC MCP_Z), a mass flowmeter (Micro Motion Elite MVD) and a pre-heater. A reservoir is used to store the fluid and to control the working pressure at atmospheric pressure.

The experimental facility is instrumented with an absolute pressure transducer (1 bar) to measure the pressure at the inlet of the test section, and a differential pressure transducer (100 mbar) to measure the pressure drop across the test section. The absolute pressures at the outlet of the condenser and at the inlet of the pre-heater are also measured. K-type thermocouples are inserted at different locations to measure the bulk fluid temperature.

\subsection{Experimental procedure}

Before each test point, degassing of water is made by boiling at saturated temperature $\left(100^{\circ} \mathrm{C}\right)$ for two hours. Then, the desired flow rate is established and the electrical power is raised in steps lasting a few minutes each until a new steady state is achieved. The flow rate, current, voltages, pressures, and bulk temperatures are monitored and recorded at each power step. The mass flux was set at $100 \mathrm{~kg} \cdot \mathrm{m}^{-2} \cdot \mathrm{s}^{-1}$ and the base heat flux was varied from 30 to $80 \mathrm{~kW} \cdot \mathrm{m}^{-2}$. All tests are performed under steady-state conditions. The experimental data are
Table 1. Operating parameters and uncertainties.

\begin{tabular}{ccc}
\hline Parameter & Range & Uncertainty \\
\hline$D_{\mathrm{h}}(\mathrm{mm})$ & 0.96 & $\pm 0.02 \mathrm{~mm}$ \\
$G\left(\mathrm{~kg} \cdot \mathrm{m}^{-2} \cdot \mathrm{s}^{-1}\right)$ & 100 & $\pm 2 \%$ \\
$P_{\text {in }}(\mathrm{mbar})$ & 1000 & $\pm 0.1 \%$ \\
$P_{\mathrm{in}}-P_{\text {out }}(\mathrm{mbar})$ & $0-100$ & $\pm 0.3 \%$ \\
$T_{\mathrm{s}}\left({ }^{\circ} \mathrm{C}\right)$ & 100 & $\pm 0.2{ }^{\circ} \mathrm{C}$ \\
$T_{\mathrm{w}}\left({ }^{\circ} \mathrm{C}\right)$ & $100-120$ & $\pm 0.2{ }^{\circ} \mathrm{C}$ \\
$q(\mathrm{~W})$ & $0-500$ & $\pm 2 \%$ \\
$h\left(\mathrm{~kW} \cdot \mathrm{m}^{-2} \cdot \mathrm{K}^{-1}\right)$ & $3-30$ & $\pm 4-7 \%$ \\
$x$ & $-0.1-0.2$ & $\pm 2 \%$ \\
\hline
\end{tabular}

recorded with a data logger (Agilent 34970A) connected to a computer.

Thermodynamic properties of water are calculated with the computer code REFPROP 7.0, developed by NIST (2002). Experimental parameters and operating conditions are summarized in Table 1. The measurement uncertainties are estimated using the error propagation law.

\section{Heat transfer measurements}

Figure 5 shows comparison of the heat transfer performances of $\mu$ - $\mathrm{SiO} x$ and $\mu$-Ti surfaces to those of $\mathrm{SiO} x$ and Ti surfaces, respectively at a mass flux of $100 \mathrm{~kg} \cdot \mathrm{m}^{-2} \cdot \mathrm{s}^{-1}$. It was observed that the structured surfaces exhibit significant enhancements in heat transfer coefficient compared to the smooth surfaces.

In comparison to $\mathrm{SiO} x$ surface, the average enhancement in heat transfer coefficient given by $\mathrm{SiO} x$ surface is about $73 \%$. Improvements are obtained with all operating heat fluxes between $40 \mathrm{~kW} \cdot \mathrm{m}^{-2}$ and $80 \mathrm{~kW} \cdot \mathrm{m}^{-2}$. It is interesting to notice that on $\mu-\mathrm{SiO} x$ surface, the evolution trend of the heat transfer coefficient with the vapour quality differs from the one on $\mathrm{SiO} x$ surface, but is similar to those on Ti surface. In other words, the heat transfer highly increases and then decreases when the vapour quality increases.

At a given heat flux, the critical vapour quality is defined as the vapour quality at which the maximum heat transfer coefficient is reached. Figure 5 shows that the critical vapour qualities of $\mu-\mathrm{SiO} x$ surface are from 0.02 to 0.03 with an average value of 0.025 . They are significantly higher than the critical vapour qualities of the other surfaces varying between 0.005 and 0.015 . Therefore, using $\mu$ - $\mathrm{SiO} x$ surface, the intermittent dryout is delayed.

In comparison to $\mathrm{Ti}$ surface, $\mu$-Ti surface shows an average enhancement in heat transfer coefficient of about 


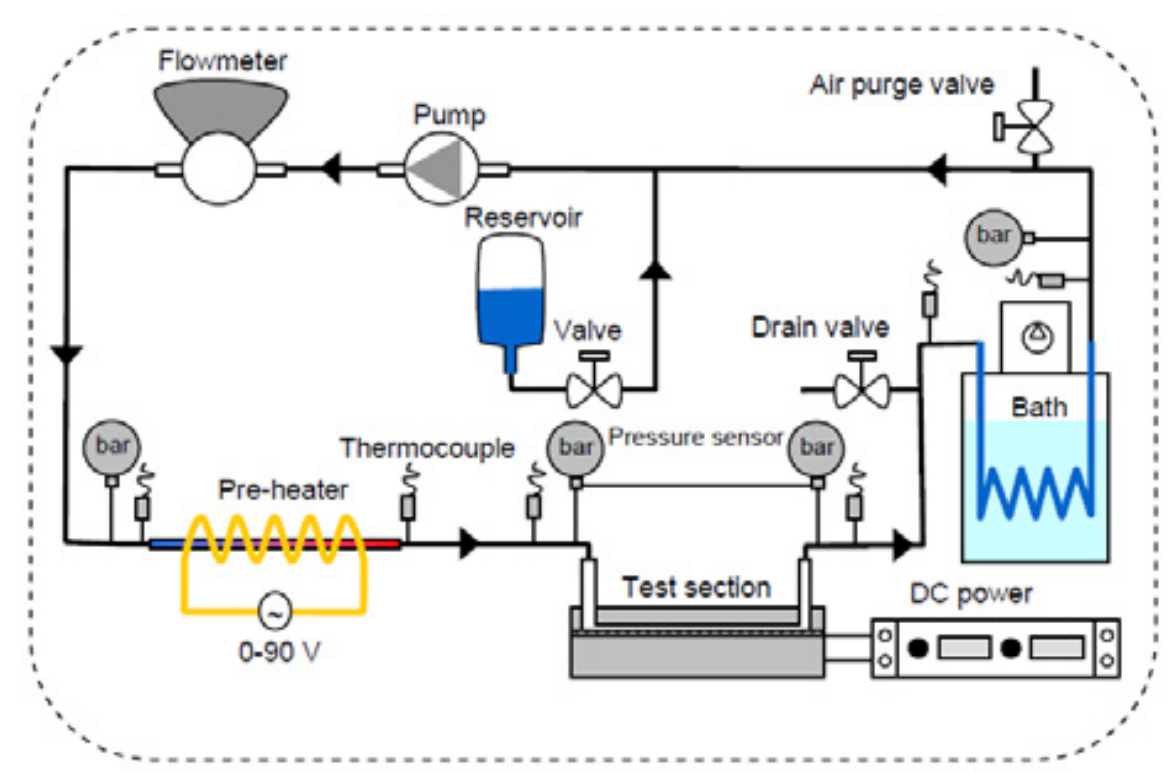

Fig. 4. Schematic view of the experimental apparatus.
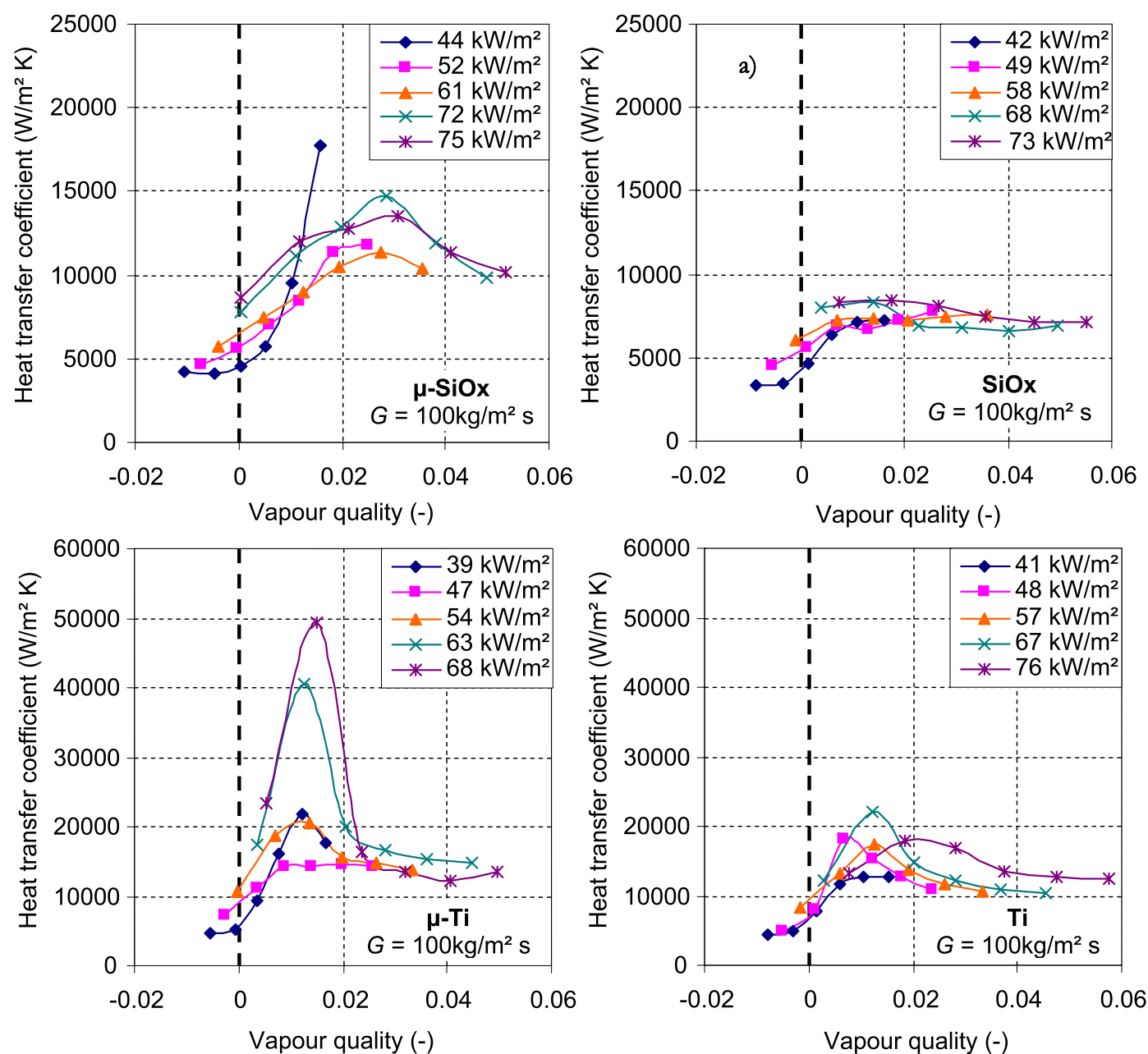

Fig. 5. Comparison of evolutions of the heat transfer coefficient with the vapour quality for the smooth and structured surfaces at $100 \mathrm{~kg} \cdot \mathrm{m}^{-2} \cdot \mathrm{s}^{-1}$. 


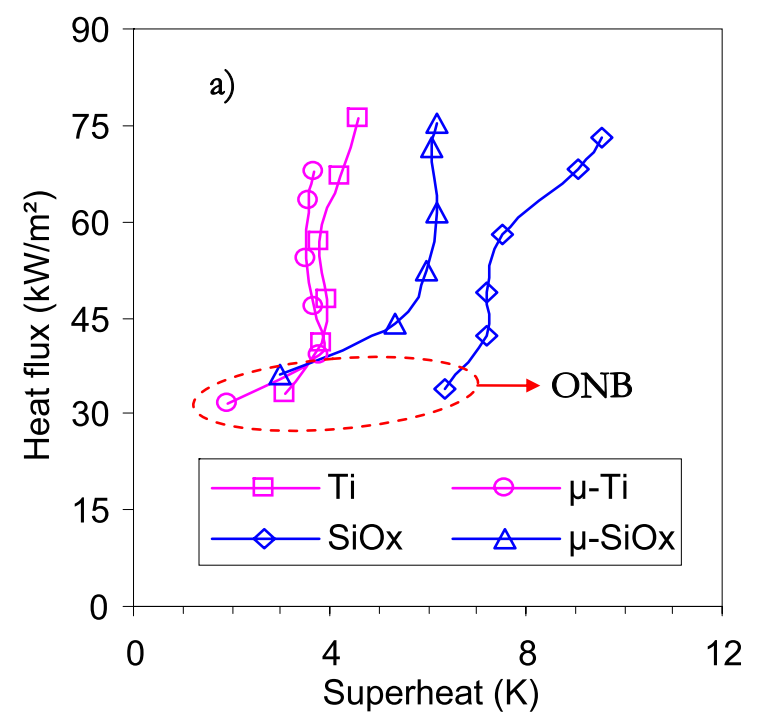

Fig. 6. Boiling curves of the smooth and structured sample surfaces at $100 \mathrm{~kg} \cdot \mathrm{m}^{-2} \cdot \mathrm{s}^{-1}$.

$85 \%$ at $100 \mathrm{~kg} \cdot \mathrm{m}^{-2} \cdot \mathrm{s}^{-1}$. Among all the sample surfaces, $\mu$-Ti surface exhibits the best heat transfer performance. Especially, its heat transfer coefficient can reach to $50000 \mathrm{~W} \cdot \mathrm{m}^{-2} \cdot \mathrm{K}^{-1}$ at heat flux of $68 \mathrm{~kW} \cdot \mathrm{m}^{-2}$.

\section{Discussions}

For flow boiling in microchannels, the main effect of micro-patterning is identified as the reduction of the superheat for onset of nucleation (ONB). This remark is highlighted by comparisons of the boiling curves for the smooth and structured surfaces, as shown in Figure 6.

In comparison with the smooth surfaces, the structured surfaces exhibit lower superheats for ONB. Especially, between $\mathrm{SiO} x$ and $\mu$-SiO $x$ surfaces, the superheat for $\mathrm{ONB}$ is reduced from about $6{ }^{\circ} \mathrm{C}$ to about $2.5^{\circ} \mathrm{C}$, which is close to the superheat for ONB of Ti and DLC surfaces. Because $\mu-\mathrm{SiO} x$ surface is highly wetted, the liquid rewetting rate on this surface is significantly higher than those of $\mathrm{Ti}$ and $\mu$-Ti surfaces. As a result, the intermittent dryout occurs on $\mu$-SiO $x$ surface at a higher critical vapour quality. Among all wetted surfaces, $\mu-\mathrm{Ti}$ surface generates the lowest superheat for ONB. This would be a reason for the best heat transfer performance obtained with this surface.

\section{Conclusions}

Experiments were performed to study the flow boiling heat transfer in a microchannel on smooth and micro-structured surfaces. The micro-structured surfaces showed significant enhancements (up to 85\%) in heat transfer compared to the smooth surfaces. Also, using the highly-wetted structured surface, the intermittent dryout is improved, i.e. the critical vapour quality at which this phenomenon occurs increases.

\section{References}

[1] P. Kew, K. Cornwell, Correlations for the prediction of boiling heat transfer in small-diameter channels, Appl. Therm. Eng. 17 (1997) 705-715

[2] S.G. Kandlikar, W.J. Grande, Evolution of microchannel flow passages-thermohydraulic performance and fabrication technology, Heat Trans. Eng. 25 (2003) 3-17

[3] N. Caney, J. Bigot, P. Marty, Experimental flow boiling study in mini-channel, 13th Int. Heat Transfer Conference, 2006, Sydney, Australia

[4] F. Madrid, N. Caney, P. Marty, Study of a vertical boiling flow in rectangular mini-channels, Heat Trans. Eng. 28 (2007) 753-760

[5] R. Ali, B. Palm, M.H. Maqbool, Flow boiling heat transfer characteristics of a minichannel up to dryout condition, 2d Micro/Nanoscale Int. Heat \& Mass Trans. Conf. 2009, Shanghai, China

[6] J.R. Thome, Boiling in microchannels: a review of experiment and theory, Int. J. Heat Fluid Flow 25 (2004) 128-139

[7] H.T. Phan, N. Caney, P. Marty, S. Colasson, J. Gavillet, Surface wettability controlled by nanocoating: The effects on pool boiling heat transfer and nucleation mechanism, I. J. Heat Mass Trans. 52 (2009) 5459-5471 